\title{
Developments in Biological Standardization
}

Vol. 36 Washington DC, 1976

Vol. 37 Geneva, 1976

Vol. 38 London, 1977

Vol. 39 Geneva, 1977

Vol. 40 Marburg, 1977

Vol. 41 Guadeloupe, 1978

Vol. 42 Paris, 1978

Vol. 43 Brussels, 1978

Vol. 44 Villars, 1979

Vol. 45 San Antonio, 1979

Vol. 46 Oxford, 1979

Vol. 47 Bilthoven, 1980

Vol. 48 Geneva, 1980

Vol. 49 Leetown, 1981

Vol. 50 Heidelberg, 1981

Vol. 51 Lyons, 1981

Vol. 52 Lyons, 1981

Vol. 53 Dublin, 1982

Vol. 54 Athens, 1982

Vol. 55 Copenhagen, 1982

Vol. 56 Algiers, 1983

Vol. 57 Paris, 1983

Vol. 58 Budapest, 1983

Vol. 59 Geneva, 1983

Vol. 60 Gardone Riviera, 1984

Vol. 61 Geneva, 1984

Vol. 62 Stockholm, 1985

Vol. 63 San Francisco, 1985

Vol. 64 London, 1985

Vol. 65 Amsterdam, 1985
Freeze-Drying of Biological Products

Standardization of Cell Substrates for the Production of Virus Vaccines Biological Preparations in the Treatment of Cancer

Influenza Immunization

Standardization of Rabies Vaccines for Human Use Produced in

Tissue Culture (Rabies III)

Vaccines in the Developing Countries

Second General Meeting of ESACT

Immunization: Benefit Versus Risk Factors

Test methods for the Quality Control of Plasma Proteins

The Standardization of Animals to Improve Biomedical Research,

Production and Control

Third General Meeting of ESACT

Reassessment of Inactivated Poliomyelitis Vaccine

Standardization of Albumin, Plasma Substitutes and Plasmapheresis

Fish Biologics: Serodiagnostics and Vaccines

The Use of Heteroploid and Other Cell Substrates for the Production of Biologicals

Immunization of Adult Birds with Inactivated Oil Adjuvant Vaccines

Herpes Virus of Man and Animal: Standardization of Immunological

Procedures

Enteric Infections in Man and Animals: Standardization of

Immunological Procedures

Viral Hepatitis: Standardization in Immunoprophylaxis of Infections by Hepatitis Viruses

Fifth General Meeting of ESCAT

Third International Symposium on Brucellosis

Monoclonal Antibodies: Standardization of their Characterization and Use International Symposium on BCG Vaccines and Tuberculins

Standardization and Control of Biologicals Produced by Recombinant DNA Technology

Production and Exploitation of Existing and New Animal Cell Substrates

Proceedings of the Fourth International Symposium on Pertussis

Diagnostics and Vaccines for Parasitic Diseases

Use and Standardization of Chemically Defined Antigens

Reduction of Animal Usage in the Development and Control of

Biological Products

Use and Standardization of Combined Vaccines 
Vol. 66 Vienna, 1985

Vol. 67 Melbourne, 1986

Vol. 68 Geneva, 1986

Vol. 69 London, 1987

Vol. 70 Arlington, VA, 1988

Vol. 71 Utrecht, 1989

Vol. 72 Annecy, 1989

Vol. 73 Shizuoka, 1990

Vol. 74 Bethesda, MD, 1990

Vol. 75 London, 1990

Vol. 76 Bethesda, MD, 1991

Vol. 77 Annecy, 1991

Vol. 78 Bethesda, MD, 1991

Vol. 79 Ploufragan, 1992

Vol. 80 Heidelberg, 1992

Vol. 81 Cannes, 1992

Vol. 82 Albany NY, 1993

Vol. 83 Annecy, 1993

Vol. 84 Langen, 1993

Vol. 85 Santa Fé, NM, 1994

Vol. 86 Langen, 1994

Vol. 87 Geneva, 1995

Vol. 88 Bethesda, MD, 1995

Vol. 89 Rome, 1995

Vol. 90 Oslo, 1996

Vol. 91 San Francisco, CA, 1996

Vol. 92 Bergen, 1996

Vol. 93 Annecy, 1996

Vol. 94 Bethesda, MD, 1997

Vol. 95 Paris, 1997

Vol. 96 Washington, DC, 1995

Vol. 97 London, 1997

Vol. 98 London, 1997

Vol. 99 Strasbourg, 1998

Vol. 100 Geneva, 1998

Vol. 101 London, 1998
Advances in Animal Cell Technology: Cell Engineering, Evaluation and Exploitation

Standardization in Blood Fractionation Including Coagulation Factors

Cells - Products - Safety

Cytokines Laboratory and Clinical Evaluation

Continuous Cell Lines as Substrates for Biologicals

Monoclonal Antibodies for Therapy, Prevention and In vivo Diagnosis of Human Disease

Progress in Animal Retroviruses

Pertussis: Evaluation and Research on Acellular Pertussis Vaccines

Biological Product Freeze-Drying and Formulation

Virological Aspects of the Safety of Biological Products

Continuous Cell Lines - An International Workshop on Current Issues

Standardization of the Immunopharmacology of Natural and Synthetic Immunomodulators

Poliovirus Attenuation: Molecular Mechanisms and Practical Aspects

The First Steps Towards an International Harmonization of Veterinary

Biologicals: 1993 and Free Circulation of Vaccines within the EEC

Transmissible Spongiform Encephalopathies - Impact on Animal and

Human Health

Virological Safety Aspects of Plasma Derivatives

Recombinant Vectors in Vaccine Development

Genetic Stability and Recombinant Product Consistency

Non-Target Effects of Live Vaccines

Genetics of Streptococci, Enterococci and Lactococci

Replacement, Reduction and Refinement of Animal Experiments in the Development and Control of Biological Products

New Approaches to Stabilisation of Vaccines Potency

Viral Safety and Evaluation of Viral Clearance from Biopharmaceuti-

cal Products

Pertussis Vaccine Trials

Fish Vaccinology

Development of Specifications for Biotechnology Pharmaceuticals

Products

Modulation of the Immune Response to Vaccine Antigens

Safety of Biological Products Prepared from Mammalian Cell Culture

Simian Virus 40 (SV40): A Possible Human Polyomavirus

Preclinical and Clinical Development of New Vaccines

Characterization of Biotechnology Pharmaceutical Products

Biological Characterization and Assay of Cytokines and Growth Factors

Inactivated Influenza Vaccines Prepared in Cell Culture

Animal Sera, Animal Sera Derivatives and Substitutes Used in the

Manufacture of Pharmaceuticals: Viral Safety and Regulatory Aspects

A Celebration of 50 Years of Progress in Biological Standardization and Control at WHO

Alternatives to Animals in the Development and Control of Biological Products for Human and Veterinary Use 


\section{Developments in Biologicals}

Vol. 102 San Francisco, CA, 1999

Vol. 103 Annecy, 1999

Vol. 104 Langen, 1999

Vol. 105 Paris, 2000

Vol. 106 Rockville, MD, 2000

Vol. 107 London, 2000

Vol. 108 Langen, 2001

Vol. 109 Washington, DC, 2000

Vol. 110 Palm Cove, 2001

Vol. 111 Utrecht, 2001

Vol. 112 Bethesda, MD, 2001

Vol. 113 Berlin, 2001

Vol. 114 Ames, IA, 2002

Vol. 115 Bergen, 2002

Vol. 116 Los Angeles, CA, 2003

Vol. 117 Langen, 2003

Vol. 118 Langen, 2003

Vol. 119 Buenos Aires, 2004

Vol. 120 Bethesda, MD, 2003

Vol. 121 Bergen, 2003

Vol. 122 Bethesda, MD, 2003

Vol. 123 Rockville, MD, 2004

Vol. 124 Paris, France, 2005

Vol. 125 Kiev, Ukraine, 2005

Vol. 126 Saint-Malo, France, 2005

Vol. 127 Sydney, Australia, 2005

Vol. 128 Florianopolis, Brazil, 2006

Vol. 129 Bergen, Norway, 2006

Vol. 130 Verona, Italy, 2007

Vol. 131 Paris, France, 2007
Advances in Transfusion Safety

Physico-Chemical Procedures for the Characterization of Vaccines

Development and Clinical Progress of DNA Vaccines

Progress in Polio Eradication: Vaccine Strategies for the End Game

Evolving Scientific and Regulatory Perspectives on Cell Substrates

for Vaccine Development

The Design and Analysis of Potency Assays for Biotechnology Products

Advances in Transfusion Safety

Biologics 2000 - Comparability of Biotechnology Products

Orphan Vaccines - Bridging the Gap

Advancing Science and Elimination of the Use of Laboratory

Animals for Development and Control of Vaccines and Hormones

Immunogenicity of Therapeutic Biological Products

Process Validation for Manufacturing of Biologics and Biotechnology

Products

Vaccines for OIE List A and Emerging Animal Diseases

Laboratory Correlates of Immunity to Influenza - A Reassessment,

Development of Therapeutic Cancer Vaccines

Consideration of Alternative Licensing Procedures for Vaccines for

Minor Species, Minor Indications and Autogenous/Autologous Products

PDA/EMEA European Virus Safety Forum

Control of Infectious Animal Diseases by Vaccination

Advances in Transfusion Safety

Progress in Fish Vaccinology

State of the Art Analytical Methods for Characterization of Biological

Products and Assessment of Comparability

Vaccine Cell Substrates 2004

OIE/FAO International Scientific Conference on Avian Influenza

First International Conference on Rabies in Europe

New Diagnostic Technology: Applications in Animal Health and

Biologics Controls

Advances in Transfusion Safety - Volume IV

First International Conference of the OIE Reference Laboratories

and Collaborating Centres

The OIE Global Conference on Aquatic Animal Health

Vaccination: A Tool for the Control of Avian Influenza

Towards the Elimination of Rabies in Eurasia 